\title{
Aborto legal o aborto desigual: Penalización del aborto a la luz de la ley de identidad de género ${ }^{1}$
}

\author{
Legal abortion or unequal abortion: \\ Criminalization of abortion in light \\ of the gender identity law
}

\author{
Estefanía Evelin Guercioni ${ }^{2}$ \\ Universidad de Buenos Aires - Argentina
}

Revista Derechos en Acción ISSN 2525-1678/ e-ISSN 2525-1686

Año 5/No 15, Otoño 2020 (21 marzo a 21 junio), 261-298

DOI: https://doi.org/10.24215/25251678e399

\section{Introducción}

En la actualidad existe un combate jurídico, ideológico y moral, que gira en torno a la legalización del acceso al aborto legal, seguro y gratuito. Más allá de la procedencia de los argumentos esgrimidos por aquellos que se encuentran a favor $y$ en contra del proyecto de legalización del aborto, no hace falta indagar mucho en ellos para toparse con fundamentos misóginos y discriminatorios -de ambos lados del debate-. En ese afán de "velar por la vida del niño por nacer" y "proteger el derecho de las mujeres a elegir sobre su propio cuerpo", se dejan de lado ciertas realidades que nos demuestran que la conducta que

\footnotetext{
Trabajo elaborado en el marco de la asignatura "Sentencia Judicial y Argumentación Jurídica" y del Proyecto DeCyT UBA, 2018-2020, "Principios Jurídicos" a cargo del Dr. Juan Pablo Alonso, Facultad de Derecho de la Universidad de Buenos Aires. Agradezco a John A. Carlín Sánchez, integrante del cuerpo docente, por la lectura y los comentarios. Los errores me pertenecen.
}

2 Estudiante de la Carrera de Abogacía de la Facultad de Derecho de la UBA. 
se intenta restringir, no se circunscribe solo al género femenino, y esto puede resultar en un castigo discriminatorio por el ejercicio de esa conducta.

En el presente trabajo, comenzaré definiendo conceptos claves para comprender el análisis expuesto; repasaré el concepto de norma, las problemáticas que se suscitan en torno a ellas, el concepto de principios, y el concepto de ley penal y cómo esta debe interpretarse en función de los elementos que la componen.

Agregando citas y comentarios de juristas reconocidos intentaré darles sustento a las afirmaciones formuladas. Las citas a Alchourrón y Bulygin nos esclarecerán qué son las normas y cuáles son los problemas que ellas presentan. Introduciendo fragmentos de Zaffaroni podré explicar cómo deben interpretarse y aplicarse las normas penales. Nuevamente con Alchourrón y Bulygin incluiré información, sobre qué son los principios y cómo es su funcionamiento.

Una vez definidos los conceptos de norma, principios, normas penales y su funcionamiento, pasaré a integrar las normas específicas en cuestión explicando cada una de ellas en sus partes pertinentes para desarrollar la idea central del trabajo.

El origen del conflicto normativo a tratar surge de la formulación normativa de los artículos 85, 86, 87 y 88 del Código Penal Argentino, que prevé la sanción de prisión para la mujer que causare su propio aborto o que prestara consentimiento para que otro se lo causare.

El mencionado conflicto encuentra fundamento en el hecho de que, hoy en día, y en virtud del derecho a la rectificación de Identidad de género, no solo las mujeres pueden resultar gestantes, y en consecuencia el aborto ya no es una práctica circunscripta solo a las mujeres.

Desde el año 2012, la Ley No 26.743 -en adelante, Ley de Identidad de Género- consagra el derecho a la identidad de género de las personas, definiendo los alcances del concepto "identidad de género", estableciendo procedimientos para el 
acceso al ejercicio de ese derecho y sancionando todo tipo de falta al trato digno de las personas, en consonancia con lo dispuesto por la Ley Nacional $\mathrm{N}^{\mathrm{o}} 23.592$-en adelante Ley contra actos discriminatorios-.

Asimismo, como la libertad sexual y la identidad de género son derechos humanos consagrados a nivel nacional e internacional, trataré lo que dicen al respecto la opinión consultiva OC-24/17 emitida por la CIDH, y jurisprudencia de la Corte Suprema de Justicia de la Nación con los fallos "Comunidad Homosexual Argentina c/ Inspección General de Justicia” y "Asociación Lucha por la Identidad Travesti - Transexual c/ Inspección General de Justicia”.

No entraré en el análisis del género como algo "natural" o "biológico" ya que es una discusión ampliamente dada y, a mi entender, resuelta en el campo de lo jurídico con la promulgación de la Ley de Identidad de Género. Me limitaré a partir de la idea de que la Ley de Identidad de género es tajante respecto de lo que se quiere decir con género, haciendo un breve análisis de esta, ya que es necesario comprender sus alcances para entender cómo esta entra en juego en el campo de la penalización del aborto.

Llegando al final de esta monografía se hará un breve análisis de lo que sucede desde el punto de vista de los sistemas normativos.

Por último, elaboraré una breve conclusión personal sobre por qué sostengo que la penalización del aborto, con la introducción de la Ley de Identidad de Género, vulnera el principio constitucional de Igualdad.

\section{Las normas y el problema de su aplicabilidad}

\section{II.A. Concepto de norma}

La obstaculización de la aplicación de las normas a los casos concretos no es propia del problema a tratar y sucede constantemente en todos los ámbitos del derecho, porque las 
normas dependen de cómo estas son formuladas y de la voluntad legislativa al promulgarlas.

La teoría jurídica examina el problema del significado de las formulaciones utilizando la concepción lingüística mixta para determinar qué es una norma.

Siguiendo la concepción lingüística mixta las normas son el resultado de la conjunción de una formulación normativa como expresión lingüística y el significado de la voluntad real del legislador, por lo tanto, las normas son enunciados significativos.

Al momento de legislar, quienes están a cargo de la creación de normas están inevitablemente limitados para observar la universalidad de casos que deben regular, por lo tanto, es imposible que el legislador le dé a la norma un significado que aplique a todos los casos concretos, sin mencionar que estos formulan normativas para casos meramente abstractos.

Las normas al ser formulaciones lingüísticas están formadas por palabras, las cuales siempre se encuentran dotadas de significados. Las significaciones dadas a las palabras son tan numerosas como la cantidad de intérpretes de las mismas, estos interpretes encuentran significados en las palabras en base a sus apreciaciones personales que dependen de factores culturales, sociales, raciales, generacionales, entre otros. Y dado que cada individuo puede hacer una interpretación meramente personal de la significación de cada palabra, y como quienes conforman los órganos creadores de normas son seres humanos individuales, es imposible que estos formulen normas que contemplen la totalidad de los casos y las interpretaciones que pueden hacerse de ellas, y es por eso que constantemente nos encontramos con conflictos interpretativos de las normas, que si no se dan por discrepancias interpretativas, se suscitan por la evolución constante del lenguaje y las sociedades destinatarias del mismo.

\section{II.A.1. Normas penales y cómo interpretarlas}

Las normas penales son normas que tienen por objeto penalizar conductas fijadas por las mismas. Es su formulación; 
dado que las todas normas son enunciados significativos, la normativa penal no es la excepción respecto de la importancia de su formulación y la voluntad legislativa que le dan origen. En la formulación de la norma penal conviven conductas y elementos, que en conjunto forman el ámbito de lo que la norma busca sancionar, y es importante identificarlas para no excederse al momento de aplicar la norma al caso concreto.

Zaffaroni al respecto de las normas penales explica:

“...no se puede averiguar el carácter delictivo de una acción sin fijar antes su probibición, (c) Su formulación legal es necesaria al derecho penal, porque sin ella éste no puede llevar a cabo una interpretación reductora del ámbito de lo probibido, que debe partir de una limitación semántica. El tipo se expresa en lenguaje y éste jamás tiene precisión limitativa. Es un error pretender que el tipo fija lo prohibido, cuando en realidad el tipo proporciona un ámbito máximo de lo probibido, que no puede exceder de su resistencia semántica pero que aun asi es enorme. Si se entendiese como probibido todo lo que cabe en el sentido literal de los tipos penales, el poder punitivo resultante sería inmenso, arbitrario $e$ insoportable, por perfecta que sea la formulación típica de cualquier código. El tipo penal no es una fórmula que define lo probibido, sino sólo una fórmula necesaria para que el derecho penal pueda interpretarla en forma reductora de los ámbitos de hipótesis de probibición."

Lo cierto es que en el ejercicio del poder punitivo muchas veces se intenta forzar el caso concreto para que este "encaje" perfectamente en el tipo legal, o viceversa, se intenta "flexibilizar" el tipo legal para que este resulte describir la conducta a analizar en el caso concreto, cuando lo correcto según un ejercicio del derecho que respete los principios de legalidad y debido proceso -los cuales en materia penal son indiscutibles criterios de aplicabilidad últimos de las leyes penales- sería analizar acabadamente el tipo legal de manera restrictiva en

3 E. R. Zaffaroni, A. Alagia, A. Slokar, Derecho Penal. Parte General, p. 434. 
función del caso concreto, para asegurarse de que la norma describe exactamente la conducta dada en el caso dado y por ende, prescribe sancionarla.

El tipo penal es un instrumento legal, en gran parte de naturaleza descriptiva. Su función es individualizar las conductas humanas penalmente relevantes y los tipos legales nos señalan cuáles son las conductas que la ley no prescribe.

El tipo es necesario en términos lógicos porque sin el tipo sería difícil determinar la antijuricidad y la culpabilidad de una conducta que si no estuviera tipificada no sería relevante jurídicamente, y sin esa determinación los tipos penales serían aplicados de manera arbitraria y sujeta a la discrecionalidad del juzgador. Pero, sobre todo -y esto es lo que nos interesa particularmente respecto del tipo- el tipo legal es predominantemente descriptivo; porque los elementos descriptivos permiten individualizar una conducta, especialmente la significación del verbo y los sujetos que las realizan y los supuestos en los cuales la conducta está penada.

Por lo que no solo nos interesan los tipos penales en función de su interpretación lingüística si no en la interpretación lingüística del tipo y fundamentalmente de sus elementos.

Asimismo, Zaffaroni realiza un análisis de los elementos del tipo que nos es enriquecedoramente útil en el presente análisis:

"...Al realizarse el juicio de tipicidad, aparecen elementos que son individualizables a través del lenguaje común (mujer, por ejemplo), del lenguaje científico (como estupefaciente) o del lenguaje jurídico (como funcionario). Se trata de elementos que son interpretables y que pueden llamarse descriptivos en atención a la tradición. Los que requieren una precisión jurídica no dejan de ser descriptivos en este sentido, dado que su naturaleza no cambia porque para precisarlos deba aludirse al derecho en lugar de hacerlo a la medicina o a la física. La discusión en cada tipo, acerca de los elementos mencionados y su interpretación, generalmente gira en torno a la opción entre un entendimiento técnico y otro 
corriente de los vocablos empleados, y es siempre una cuestión de extensión de los conceptos interpretables, o sea, de elección entre conceptos que tienen la misma naturaleza." ${ }^{4}$

El problema es que los tipos son a veces absolutamente descriptivos. Cuando los artículos 85, 86, 87 y 88 del Código Penal se refieren a la "mujer", precisar lo que es una mujer parecería no requerir valoración alguna porque el concepto de mujer es descriptivo. Es que los artículos 85, 86, 87 y 88 del Código Penal al introducir el concepto “mujer" como elemento necesario del tipo, deja fuera una numerosa cantidad de casos donde pueden existir abortos, que en los hechos no son necesariamente son consentidos o practicados por una mujer.

Lo que sucede respecto de la tipicidad contenida en los artículos 85, 86, 87 y 88 del Código Penal y su elemento limitador no es un problema de interpretación, porque el elemento "mujer" no es vago ni ambiguo -o al menos no es en lo que nos ocupa en este trabajo, porque existen precisiones jurídicas como la ley de identidad de género que nos fijan la pauta de cómo interpretar ese elemento-, sino que el elemento del tipo incluido en dicho articulado circunscribe la penalización de la conducta a una sola categoría de personas que pueden realizarla y las sanciona por su ejercicio, dejando afuera a aquellas personas que por un tecnicismo no entran en esa agrupación categórica, pero aún pueden realizar la conducta típica sin tener ninguna clase de consecuencia penal.

Ese tecnicismo da como resultado que, el aborto hoy en día, solo se encuentra penado en los casos donde la persona gestante que aborta es una mujer, sin tener en cuenta que no todos los gestantes actualmente y a los ojos de la ley, son mujeres. Como resultado de esa inobservancia respecto de la ley de identidad género y la pauta jurídica que de ella se puede inferir, de que mujer es quien se auto percibe como tal: ¿Obtenemos un

$4 \quad$ Ibídem, p. 437 
trato discriminatorio, donde solo las gestantes que a los ojos de la ley son mujeres son penadas por abortar?

Ahí es donde comienza el conflicto jurídico: los artículos 85, 86, 87 y 88 del Código Penal -interpretada a la luz de lo dispuesto por la ley de identidad de género- y el principio de igualdad.

\section{II.A.2. La norma penal, su pertenencia a un sistema jurídico y su aplicabilidad}

El Código Penal con el que actualmente trabajamos los juristas y los estudiantes de derecho, no solo data del año 1921, si no que, también ha tenido, numerosas reformas hasta hoy, producto también de los cambios constantes dentro de la sociedad. Tantas fueron las reformas que ha perdido coherencia y se alteraron a las claras la proporcionalidad de las escalas penales y la tipificación de delitos. Un ejemplo de ello es la desproporcionalidad de las penas de los artículos 163 inciso $6^{\circ}$ ) y 119 primer párrafo del Código Penal, donde el delito de hurto de automóviles del artículo 163 inciso $6^{\circ}$ ) conlleva una sanción de 1 a 6 años de prisión, mientras el delito de abuso de menores del artículo 119 primer párrafo prevé una sanción de 6 meses a 4 años, por lo que el abuso de menores podría tener una pena menor que el hurto de un automóvil, poniendo la protección de la propiedad privada por encima de la integridad sexual de un menor.

El Código Penal no solo sufrió varias modificaciones, con el avance del tiempo se sancionaron leyes penales, y leyes que no son necesariamente penales pero que atraviesan directamente el lenguaje de las que sí lo son. Esto genera que la interpretación de las normas se vea afectada, y que gracias a ellas la voluntad legislativa termine en un entuerto respecto de la formulación normativa que sirve como medio lingüístico para la norma y el significado que el legislador pretendió atribuirle al enunciado normativo. Estas leyes no se encuentran integradas al Código y en consecuencia se origina una dispersión normativa que no guarda lógica con la codificación penal. 
En total, a la fecha, el Código Penal de 1921 ha sufrido unas novecientas reformas parciales, para darnos como resultado el maltratado y casi irreconocible Código Penal Argentino.

Los problemas en relación con las normas que existen en el momento de la promulgación o derogación de otras normas, que dificultan la operatividad de las primeras, también son gajes de las ciencias jurídicas, y esto sucede porque los sistemas jurídicos son momentáneos. Cada vez que una nueva norma es agregada a un sistema jurídico, nos encontramos frente a un sistema diferente, porque el conjunto de normas que pertenecen al sistema es distinto.

En el caso de análisis nos encontramos inevitablemente frente a dos sistemas jurídicos 5 : el Sistema S1, donde el Código Penal con sus artículos 85, 86, 87 y 88, y la Constitución Nacional de 1994, con el principio de igualdad consagrado en su artículo 16, se encuentran vigentes; y el Sistema S2, donde los artículos 85, 86, 87 y 88 del Código Penal y el artículo 16 de la Constitución Nacional continúan vigentes, pero con la particularidad de que ahora se encuentra promulgada la ley de identidad de género, que también se encuentra vigente en el sistema S2.

\section{Gráfico de sistemas S1 y S2:}

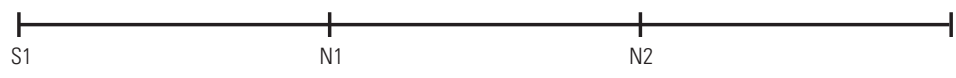

S1: Sistema 1

N1: artículos 85, 86, 87 y 88, Cód. Penal

N2: artículo 16, Constitución Nacional 1994

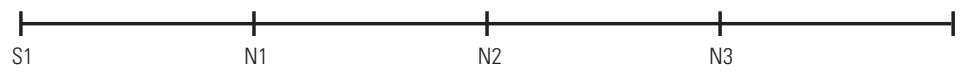

S1: Sistema 2

N1: artículos 85, 86, 87 y 88, Cód. Penal

N2: artículo 16, Constitución Nacional 1994

N3: Ley 26.743 de Identidad de Género

5 Donde en S1 se refleja la existencia simultanea de N1 y N2. En S2, la existencia simultánea de N1, N2, y N3 conforma un nuevo sistema de normas distinto de S1. 
El segundo sistema nos deja con un problema de aplicabilidad de las normas; porque la aplicabilidad de los Artículos 85, 86, 87 y 88 del Código Penal a la luz de la ley de identidad de género, es incompatible con el principio de igualdad consagrado en la Constitución Nacional, que sirve como criterio de aplicabilidad.

$\mathrm{Al}$ respecto de la relación entre vigencia y aplicabilidad de una norma, Eugenio Bulygin introduce términos como "tiempo interno" y "tiempo externo" de las normas, y nos explica cómo estos funcionan:

“...las normas se refieren también a acontecimientos temporales. El tiempo en que los diferentes acontecimientos relevantes para un caso tienen lugar es determinante de la aplicabilidad de las normas a ese caso. La secuencia de todos los momentos temporales en los que la norma es aplicable a algún caso se llamará tiempo interno de la norma. El tiempo externo de la norma es una función de su pertenencia al sistema, el tiempo interno es una función de su aplicabilidad. Tiempo externo e interno de una norma no tienen por qué coincidir necesariamente. Una norma puede existir en un sistema o en varios sistemas sucesivos sin ser aplicable y viceversa...". 6

El que una norma pertenezca a S1 o S2 no es determinante de su aplicabilidad. Pero si tenemos en cuenta que existen criterios de aplicabilidad que también forman parte del sistema jurídico vigente, y estos se contraponen con las normas que también existen dentro de ese sistema jurídico, esas normas que no cumplen con los criterios de aplicabilidad no serían aplicables al caso concreto; en nuestro caso aunque los artículos 85, 86, 87 y 88 del Código Penal se encuentran vigentes en S2 (tiempo externo) los mismos no son aplicables (tiempo externo) por la vigencia en S2 de la ley de identidad de género y del principio de igualdad como criterio de aplicabilidad.

6 Alchourrón \& Bulygin, "Tiempo y Validez", p.199. 


\section{II.B. Principios y su función como criterios de aplicabilidad}

Se entiende por principios constitucionales o fundamentales, aquellas prescripciones que contienen directrices generales que delimitan el alcance axiológico y político de un determinado orden jurídico; son verdaderas normas jurídicas y forman parte integral del ordenamiento jurídico constitucional y como tal tienen el alcance de asegurar la permanencia y obligatoriedad del contenido material de la constitución.

Los criterios de aplicabilidad son meta normas de un nivel superior al resto de las normas, dirigidas a los jueces para que estos a través de ellas puedan establecer que norma de primer nivel es aplicable a un caso concreto. ${ }^{7}$

Los criterios de aplicabilidad fijan los momentos importantes, donde se determina qué normas pertenecientes a los sistemas que corresponden en esos momentos deben compararse.

A su vez establecen relaciones jerárquicas entre esas normas pertenecientes a sistemas distintos e imponen a los jueces el deber de aplicar aquella norma que resulte superior a las demás de acuerdo con esas relaciones jerárquicas.

Los criterios de aplicabilidad tienen diversos orígenes, y el criterio de aplicabilidad que nos interesa puntualmente en el caso de análisis es el que surge del artículo 16 de la Constitución Nacional; el principio de igualdad ante la ley.

\section{II.C. Conflictos entre normas y principios}

Establecidos los conceptos de norma, norma penal y su interpretación en materia penal, y el concepto de principios como criterios de aplicación de las normas, podemos decir que la forma de interpretar las normas penales debe someterse a los principios como esos criterios de aplicabilidad de las normas. También podemos decir que la función de estos principios es evitar el ejercicio desmedido por parte del estado del poder

\footnotetext{
7 Ibídem, p. 203.
} 
punitivo, y garantizar que la norma sea ejecutada de la manera más "justa" posible.

Se observa en el presente análisis, que la conducta penada -en nuestro caso concreto, abortar- presenta un grave problema de la formulación normativa construida en abstracto, afectando la aplicabilidad de la norma penal en los casos concretos donde la conducta se reproduce, pero queda excluida la sanción por no cumplirse con uno de los elementos del tipo.

La interpretación de los artículos 85, 86, 87 y 88 del Código Penal, en función de la Ley de Identidad de Género, debe darse sobre la base de que existe un criterio de aplicabilidad que lo condiciona: el principio de igualdad.

Un sistema cambia porque se modifica alguna de sus consecuencias normativas, deja de ser el mismo sistema para convertirse en otro distinto del anterior.

Al introducirse una facultad implícita de la que antes no gozaban los seres gestantes -la de abortar y verse exento de las penas de los artículos 85, 86, 87 y 88 por haber ejercido el derecho de rectificación del género- se origina un nuevo sistema por modificarse las consecuencias normativas del sistema anterior.

\section{II.D. El caso de análisis}

II.D.1. Consideraciones previas sobre el caso de análisis

Está claro que desde la promulgación de la Ley de Identidad de Género el sistema normativo argentino no es el mismo. Lo interesante del caso es que la sanción de la Ley de Identidad de Género no sólo surtió los efectos perseguidos por el legislador, sino que también modificó el estatus jurídico de la penalización del aborto, creando una nueva categoría de personas que son capaces de gestar vida en su vientre e interrumpir esa gestación de manera voluntaria, sin ser alcanzadas por el tipo penal que persigue la sanción de esa conducta. Estas personas se encuentran en una circunstancia que las posiciona en una situación distinta y que las favorece respecto de las mujeres que abortan, 
ya que a raíz del ejercicio de un derecho como la rectificación del género, y sin quererlo, se evaden las consecuencias jurídicas de una conducta delictiva a los ojos de la ley; mientras los gestantes que son hombres trans abortan y no les cabe sanción alguna por no encontrarse mencionadas en la norma que penalizan la conducta, aquellas personas gestantes que son mujeres serían penadas por el ejercicio de la misma conducta de abortar.

Resulta necesario aclarar que no es la rectificación del género una técnica de evasión de la ley, si no que en todo caso lo problemático es la falta de instrucción legislativa respecto de las temáticas en conflicto.

Desde el punto de vista de las normas, la Ley de Identidad de Género no solo generó un cambio en la base del sistema normativo en cuanto a la aplicación de los criterios de aplicabilidad -en nuestro caso de estudio, del principio de igualdad-, sino también en las reglas de inferencia, pues se crean nuevas situaciones jurídicas probables que permiten descartar la aplicación de las penas.

Todo lo expuesto ut-supra, constituye un vacío o laguna jurídica, en cuanto a que no se encontraría ni legislada ni regulada la conducta de la persona que se auto percibe como hombre, pero aún conserva la capacidad reproductiva del cuerpo femenino y decide abortar.

Kelsen expresó respecto de las llamadas lagunas lógicas que “...En el caso de la imposicbilidad de aplicar el derecho vigente en un caso concreto porque ninguna norma jurídica indica la conducta debida. Y si en algunos casos se habla no obstante de una laguna del derecho, no es porque una decisión sea lógicamente imposible ante la falta de disposiciones aplicables, sino simplemente porque la decisión lógicamente posible aparece al órgano encargado de aplicar el derecho a tal punto inoportuna o injusta que él se inclina a admitir que el legislador no ha pensado en ese caso, y si hubiera tomado una decisión diferente de la que resulta del derecho vigente."

8 Kelsen, Eudeba, Teoría pura del derecho, pp. 172-173. 
Siendo más específicos, en este caso nos topamos con una laguna axiológica. Una laguna axiológica no es una simple laguna normativa; la laguna axiológica surge cuando una norma jurídica contempla algo que la sociedad no considera moralmente correcto, o viceversa, cuando la norma no contempla una determinada situación de hecho que necesita ser regulada debido a un aspecto moral. Las lagunas axiológicas se dan cuando la injusticia de la solución existe porque debería tomarse como relevante una propiedad que para el derecho no lo es:

"En este sentido, revisten particular importancia sus definiciones de los conceptos de laguna normativa, esto es, un caso definido en términos de las propiedades que han sido consideradas relevantes por la autoridad normativa al cual no se le ha correlacionado solución normativa alguna, y de laguna axiológica, que se produciría cuando, pese a la existencia en el sistema jurídico de referencia de una solución para cierto caso, tal solución es considerada axiológicamente inadecuada debido a que la autoridad normativa no ba tomado como relevante cierta distinción que debería haber sido tomada en cuenta."

En el caso concreto, el juez admitirá o no la existencia de elementos suficientes para considerar que el imputado es pasible de ser condenado por los artículos 85, 86, 87 y 88 del Código Penal de la Nación, observando cuales son las propiedades relevantes del caso, y teniendo en cuenta el principio de igualdad como criterio de aplicabilidad de este.

II.D.2. Normas específicamente relevantes para el caso de análisis

\section{D.2.1. El Principio de Igualdad}

El principio de igualdad ante la ley es el principio constitucional que establece la irrelevancia de prerrogativas de sangre o de nacimiento, no admite títulos personales ni de nobleza, y

9 Rodríguez, "Lagunas axiológicas y relevancia normativa", p. 349. 
consagra la igualdad de todos los habitantes ante la ley, y la admisibilidad de estos en los empleos sin otra condición que la idoneidad.

La fuente normativa del principio de igualdad ante la ley surge del texto constitucional en su artículo 16.

La igualdad puede ser considerada de 3 maneras:

\section{D.2.1.1. Igualdad de trato ante la ley formal}

Esta es la interpretación tradicional de igualdad ante la ley. Todos los que forman parte de un mismo grupo conformado por el legislador deben tratarse de la misma manera. Sin embargo, no tenemos grado preciso de la validez de esa agrupación, ni cómo deben tratarse a los individuos incluidos en ella, ni qué características deben tener en común. Es la interpretación más restrictiva del artículo 16.

\section{D.2.1.2. Igualdad de trato ante la ley material o como no discriminación arbitraria}

La falta de precisión de la característica relevante, como para realizar la distinción que el Estado cometerá en su afán de regular el ejercicio de un derecho, le da origen a la idea de igualdad de trato ante la ley como discriminación no arbitraria.

Para perfeccionar el principio de "igualdad de trato en las mismas circunstancias", deben determinarse de forma razonable las circunstancias elegidas como criterio para el trato diferente. Un criterio razonable que avalaría el trato diferente sería aquel que se relacione directamente con el fin de la norma, para que se pueda afirmar que no se viola el principio de igualdad si todos se encuentran en igualdad de circunstancias se los trata de igual forma -circunstancias relevantes, porque la circunstancia es el requisito mínimo para acceder a ese trato igualitario-. Pero este trato "genérico o neutral" parecería esconder la idea de que tratar a las personas de la misma manera significa tratarlos con igualdad, dejando de lado que en los hechos las desigualdades fácticas dejan a la idea de igualdad como un término abstracto 
e inútil. No se tiene en cuenta la desigualdad fáctica a la que se enfrentan los sujetos de derecho en la realidad, sobre todo en los casos concretos, podemos identificar ese problema respecto de la existencia de mujeres que tienen capacidad de gestar y por lo tanto de provocarse un aborto, y por otro lado, la existencia de hombres trans biológicamente capaces para gestar y consecuentemente capaces para provocarse un aborto de igual manera.

\section{II.D.2.1.3. Igualdad fáctica o discriminación positiva}

El término discriminación positiva hace referencia a aquellas medidas cuya finalidad es reducir las prácticas discriminatorias en contra de sectores históricamente excluidos.

Para considerar la situación fáctica de quien es víctima de la desigualdad, no solo en los hechos, sino también en situaciones de exclusión social o de sometimiento por pertenecer a un grupo discriminado (en nuestro caso, las mujeres y las personas trans), se evalúa la situación particular de la persona, pero como parte del grupo discriminado. Esta forma de entender la desigualdad fue introducida en el artículo 16 de manera indirecta con la incorporación de medidas de acción positiva del artículo 75 inciso 23 a la Constitución Nacional en su más reciente reforma.

El artículo 75 inciso 23, consagra la facultad legislativa de promover medidas de acción positiva que garanticen una verdadera igualdad de oportunidades y de trato, y el pleno goce y ejercicio de derechos constitucionales y de tratados internacionales vigentes, respecto de derechos de los niños, las mujeres, los ancianos, personas discapacitadas, entre otros.

\section{II.D.2.2. El derecho a la identidad de género como derecho humano}

Los derechos humanos son un conjunto de premisas y/o derechos que le dan a todo ser humano la prerrogativa de ser respetado como tal y con todos los atributos de su humanidad. Los mismos pueden ser clasificados en: derecho a la dignidad y sus derivados (intimidad, honor, conciencia, etcétera); a la 
vida (salud, etcétera); libertad, identidad, a la información, a la asociación, entre otros. Podemos afirmar que los derechos humanos se encuentran claramente alcanzados por el principio de igualdad y los incluye, con el fin de que todos los sujetos de derecho sean tratados como iguales, permitiendo su convivencia pacífica en sociedad.

El concepto de derechos humanos siempre abarcó un amplio abanico de derechos que se daban por sentado en la sociedad, pero con el avance de este concepto los derechos humanos fueron también mutando en su entidad y composición.

Con ese avance de las civilizaciones y los derechos humanos que estas consagran también surgieron normativas internacionales plasmadas en tratados internacionales que vinculan a los Estados que los ratifican al cumplimiento de ellos por sobre sus ordenamientos jurídicos.

La reforma de nuestra Constitución en el año 1994 derivó en una modificación importante en nuestras fuentes normativas, teniendo en cuenta que se le otorgó jerarquía de carácter constitucional a los Tratados sobre Derechos Humanos en el artículo 75 inciso $22,2^{\circ}$ y $3^{\circ}$ párrafo.

Uno de los tratados sobre Derechos Humanos más importante de los que se encuentran consagrados en nuestro texto constitucional es el Pacto de San José de Costa Rica (Convención Americana sobre Derechos Humanos -CADH-). Según el artículo 33 inc. b del mismo, es competente para conocer de los asuntos relacionados con el cumplimiento de los compromisos contraídos por los Estados Partes en esta Convención, la Corte Interamericana de Derechos Humanos, la que se encuentra legitimada para brindar su interpretación de la Convención o de otros tratados concernientes a la protección de los derechos humanos en los Estados Americanos, cuando sea consultada por los Estados miembros de la Organización, conforme el artículo 64 de la misma Convención. Estas consultas de los Estados miembros a la Corte Interamericana son evacuadas a través de Opiniones Consultivas. 
En la opinión consultiva OC-24/17 del 24 de noviembre de 2017 solicitada por Costa Rica, la corte se pronunció respecto de: Identidad de género, e igualdad y no discriminación a parejas del mismo sexo, obligaciones estatales en relación con el cambio de nombre, la identidad de género, y los derechos derivados de un vínculo entre parejas del mismo sexo (interpretación y alcance de los artículos 1.1., 3,7, 11.2, 13, 17, 18 y 24 , en relación con el artículo 1 de la convención americana sobre derechos humanos). Son clave las palabras de la $\mathrm{CIDH}$ cuando expresa:

“... las personas LGBTI también sufren de discriminación oficial, en "la forma de leyes y politicas estatales que tipifican penalmente la bomosexualidad, les probíben ciertas formas de empleo y les niegan acceso a beneficios, como de discriminación extraoficial, en la forma de estigma social, exclusión y prejuicios, incluso en el trabajo, el hogar, la escuela y las instituciones de atención de la salud". Por ejemplo, todavía existen varios Estados de la región en los que se criminalizan las relaciones sexuales consensuales entre personas adultas del mismo sexo en privado, lo cual ha sido considerado por esta Corte $y$ por diversos órganos de protección del derecho internacional de los derechos humanos como contrario al derecho internacional de los derechos humanos por violar los derechos a la igualdad y no discriminación, así como el derecho a la privacidad. Aunado a ello, este tipo de normas repercuten negativamente en la calidad de los servicios de salud, disuaden a las personas de recurrir a esos servicios, y pueden llevar a que se deniegue la atención o a que no existan servicios que respondan a las necesidades sanitarias específicas de las personas LGBTI e intersexuales. Además, en las jurisdicciones en las que se penaliza su comportamiento sexual, es mucho más probable que se supriman medidas preventivas que debieran ser ajustadas especificamente a estas comunidades. De la misma manera, el temor de ser juzgados $y$ castigados puede disuadir a quienes practican un comportamiento homosexual de acceder a los servicios 
de salud. Estos problemas se agravan en el caso de las personas que viven con el VIH/SIDA98. Asimismo, el ACNUDH ha encontrado que, como consecuencia de este tipo de normas, es frecuente que las víctimas se muestren reacias a denunciar los actos de violencia perpetrados por un familiar por temor a las consecuencias penales que acarrearía la revelación de su orientación sexual." 10

La cita anterior es a todas luces clara cuando señala que el derecho a la identidad sexual y de género es indiscutiblemente un derecho humano, que se ve gravemente afectado por los impedimentos que sufren las personas LGBTI e intersexuales, y como ello puede repercutir en su vida sexual, afectiva, personal, privada y hasta familiar.

Respecto de los derechos humanos en el ordenamiento jurídico interno, también en la jurisprudencia de la Corte Suprema, se puede advertir la recepción de algunas de las doctrinas y tesis protectorias de los derechos humanos, específicamente del derecho a la elección libre del género y la sexualidad.

Si bien el poder legislativo es el poder al que le incumbe la sanción de normas, se encuentra en cabeza del poder judicial el control constitucional de las normas sancionadas, ya que es custodio de los valores básicos del sistema político jurídico, y el medio de ejercicio de ese control son los fallos que estos emiten. Así, la Corte Suprema debe ejercer ese control respetando la Ley Fundamental tanto en las facultades que esta le asigna al órgano creador de normas, como en el texto de esta que consagra la jerarquía constitucional de los derechos humanos.

Existen dos fallos centrales de jurisprudencia de la Corte Suprema de Justicia de la Nación donde se tratan discusiones en torno a los derechos de las comunidades LGBTI e intersexuales.

En el fallo "Comunidad Homosexual Argentina c. Resolución Inspección General de Justicia" (en adelante CHA) donde se discute si es ajustada a derecho la negativa de la Inspección

10 Corte IDH, Opinión consultiva OC-24/17. 
General de Justicia al otorgamiento de personería jurídica requerido por la Comunidad Homosexual Argentina.

Luego de transitar todas las instancias previas, sin obtener la personería jurídica requerida, la CHA tuvo que promover recurso extraordinario ante la Corte Suprema de la Nación como última instancia para lograr el reconocimiento de su derecho como asociación, instancia en la cual, nuevamente recibió la negativa a su petitorio.

Uno de los votos que confirmó la resolución de la IGJ y de la Cámara de apelaciones denegando la personería, fue el del Dr. Belluscio, quien consideró que la asociación de la comunidad homosexual nada tenía que ver con el "bien común" y negó que estos sufrieran algún tipo de discriminación:

"El art. 33 del Código Civil, contrapone el bien común, esto es el de la sociedad en general, al interés particular de los individuos que crean la entidad, cuando exige que el primero sea el principal objeto de la asociación o fundación para que se autorice su funcionamiento como persona jurídica de carácter privado. En los Estatutos de la peticionante no resulta que su principal objeto sea el exigido por la ley. Por el contrario, se presenta como primordial el bien de sus propios integrantes, que parecen querer entablar su propia defensa contra una supuesta discriminación. Independientemente del juicio moral que pueda merecer una desviación del instinto sexual cuyos orígenes, no están bien precisados, tal discriminación no se da en nuestro país, donde -a diferencia de otros, inclusive en EUA donde la sodomía es delito cuya represión ha sido admitida como constitucional por la Corte- nunca ha existido punición penal de la homosexualidad y personas que padecen tal desviación han ocupado destacados lugares en la vida artística, literaria y aún científica. La ausencia de interés social es marcada en ciertos campos en donde se pretende excluir la discriminación, pues algunos son totalmente ajenos al legislador-que podría por ejemplo so color de impedir discriminación religiosa, imponer a una comunidad religiosa, la aceptación de 
sacerdotes homosexuales- $y$ otros resulta dificil interpretarlos ya que no se comprende en que consiste la "discriminación en lo familiar", pues tampoco parece aconsejable, poner en un pie de igualdad a personas de conducta sexual desviada frente a instituciones como la adopción, tutela, aunque no se llegue al extremo de legalizar uniones homosexuales seudomatrimoniales. Aun cuando se admitiese que el concepto constitucional de bien común es que sostiene la recurrente ("todo aquello que haga posible que toda persona desarrolle plenamente sus potencialidades tendiendo al logro de su propia perfección") no se advierte cual es la perfección que pueda alcanzarse mediante el desarrollo de la homosexualidad. La denegación de personalidad jurídica solicitada por la recurrente no viola derecho constitucional de asociarse con fines útiles. Tampoco está violada la ley 23.592 ya que la denegación no se funda en la condición de bomosexual de los peticionantes, sino en el objeto de la entidad que pretende crear." 11

Lamentablemente la CHA no pudo acceder a la personería pretendida. Del mismo fallo destacamos el voto en disidencia del Dr. Fayt, el que reivindicó los derechos de la comunidad homosexual a su protección, asociación, a la privacidad y a su dignidad, entre otros:

"Frente a la existencia de un grupo de personas, que pueden resultar afectadas en su dignidad, la que merece claramente protección constitucional, es legítima su organización a los efectos de la preservación de aquella. La protección de ese valor rector, la dignidad humana implica que la ley reconozca, en tanto no ofenda al orden y la moral pública, ni perjudique a un tercero, un ámbito intimo e infranqueable de libertad, de modo tal que pueda conducir a la realización personal, posibilidad que por otra parte es requisito en una sociedad sana." (...) "La protección del ámbito de privacidad resulta uno

11 CSJN, “Comunidad Homosexual Argentina c. Resolución Inspección General de Justicia”, disidencia del Dr. A. C. Belluscio. 
de los mayores valores del respeto a la dignidad del ser humano y un rasgo de esencial diferenciación entre el estado de derecho y las formas autoritarias de gobierno. Este es el sentido esencial que se le debe otorgar a lo que se ha dado en llamar el "derecho de las minorias" consagrado en constituciones modernas y que se induce en diversas disposiciones de la nuestra, arts. 16 y 19."12

En disidencia también el Dr. Petracchi sostuvo:

“...las conclusiones de la IGJ acerca de que tal condición importa una anomalía psicológica y afecta, además, considerada en sí misma, la moral, las buenas costumbres, así como las bases de la institución familiar, por lo que aquella pública defensa no se compadece con las exigencias del bien común, en modo alguno resulta arbitraria. En primer lugar, no se ha comprobado que esa pública defensa deba ser atendida como apología -alabanza, sino más bien como la lucha contra todo tipo de discriminación que pudiera afectar a las personas homosexuales, por lo cual dicha pública defensa se encuentra amparada por el art. 14 CN."13

Por otro lado, distinto fue el caso del fallo de Corte "Asociación Lucha por la Identidad Travesti - Transexual c/ Inspección General de Justicia.", donde también era pretendida la personería jurídica por la Asociación Lucha por la Identidad Travesti-Transexual, contra la resolución denegatoria de la IGJ y confirmación de la misma por la Cámara de Apelaciones en lo civil, cuya sentencia resultó favorable para la actora:

“...el bien colectivo tiene una esencia pluralista, pues sostener que ideales como el acceso a la salud, educación, trabajo, vivienda y beneficios sociales de determinados grupos, así como propender a la no discriminación, es sólo un beneficio propio de los miembros de esa agrupación, importa olvidar que esas prerrogativas son

\footnotetext{
12 Ibídem, disidencia del Dr. C. FAYT.

13 Ibídem, disidencia del Dr. E. S. Petracchi.
} 
propósitos que hacen al interés del conjunto social como objetivo esencial y razón de ser del Estado de cimentar una sociedad democrática, al amparo de los arts. 14 y 16 de la Constitución Nacional y de los tratados internacionales incorporados en su art. 75, inc. 22."(...)"Por respetable que sea la opinión personal de los jueces, ésta no puede prevalecer sobre las normas constitucionales $n i$ con ellas se puede nutrir la elaboración dogmática de un concepto a partir del Código Civil en forma contraria a la Constitución Nacional y a los tratados internacionales a ella incorporados." 14

También en esta sentencia se pronunció a favor de la actora el Dr. Fayt:

"...sostener, como lo hace el tribunal a quo, que el goce de igualdad de oportunidades de un sector determinado no hace al bien común de toda la sociedad configura una negación de aquella prerrogativa y una verdadera discriminación, inadmisible en un tribunal de justicia, que contradice los fundamentos de normas federales, como la ley antidiscriminatoria 23.592, sin explicar el fundamento que habilitaría al Estado a conceder ciertos beneficios a unos y no a otros, ni dar un criterio objetivo o parámetros constitucionales que permitan conocer explícitamente las condiciones requeridas para ello... También considera irrazonable el actuar del Estado en tanto reconoce personalidad a determinados grupos, con una identidad sexual definida-comunidad homosexualpero se la deniega en idénticas condiciones a otro, como es el conformado por los travestis y transexuales." 15

Mientras por un lado se acogen por los tribunales, la doctrina y la jurisprudencia los principios generales de los derechos humanos, otras normativas han surgido y están vigentes, y generan incoherencias con los principios generales del individuo.

14 CSJN, "Asociación Lucha por la Identidad Travesti - Transexual c/ Inspección General de Justicia".

15 Ibídem, voto del Dr. C. FAYT. 
En este orden de ideas nos introducimos en el ejemplo elegido para desarrollar el presente trabajo: la incoherencia entre la vigencia y aplicación de los artículos $85,86,87$ y 88 del Código Penal en el caso de las mujeres que abortan, y la inobservancia de la probable existencia de hombres trans que abortan, dejando sin efecto las protecciones de la Ley de Identidad de Género, de la Ley n ${ }^{\circ} 23.592$-en adelante Ley contra actos discriminatorios-, del Pacto de San José de Costa Rica, y del principio de igualdad ante la ley de los ciudadanos consagrado en la Constitución Nacional.

\section{II.D.2.3. La penalización del aborto}

La prohibición de la práctica del aborto en la mujer se encuentra regulada en los artículos 85 a 88 del Código Penal Argentino, los cuales expresan que:

"ARTÍCULO 85. - El que causare un aborto será reprimido:

$1^{\circ}$ Con reclusión o prisión de tres a diez años, si obrare sin consentimiento de la mujer. Esta pena podrá elevarse hasta quince años, si el hecho fuere seguido de la muerte de la mujer.

$2^{\circ}$ Con reclusión o prisión de uno a cuatro años, si obrare con consentimiento de la mujer.

El máximum de la pena se elevará a seis años, si el hecho fuere seguido de la muerte de la mujer.

ARTÍCULO 86. - Incurrirán en las penas establecidas en el artículo anterior y sufrirán, además, inhabilitación especial por doble tiempo que el de la condena, los médicos, cirujanos, parteras o farmacéuticos que abusaren de su ciencia o arte para causar el aborto o cooperaren a causarlo.

El aborto practicado por un médico diplomado con el consentimiento de la mujer encinta, no es punible:

$1^{\circ}$ Si se ha becho con el fin de evitar un peligro para la vida o la salud de la madre y si este peligro no puede ser evitado por otros medios. 
$2^{\circ}$ Si el embarazo proviene de una violación o de un atentado al pudor cometido sobre una mujer idiota o demente. En este caso, el consentimiento de su representante legal deberá ser requerido para el aborto.

ARTÍCULO 87. - Será reprimido con prisión de seis meses a dos años, el que con violencia causare un aborto sin haber tenido el propósito de causarlo, si el estado de embarazo de la paciente fuere notorio o le constare.

ARTÍCULO 88. - Será reprimida con prisión de uno a cuatro años, la mujer que causare su propio aborto o consintiere en que otro se lo causare. La tentativa de la mujer no es punible."

Por lo expuesto en todos los artículos anteriores se determina que será obligatorio sancionar cuando la mujer gestante se provocare su propio aborto o prestara consentimiento a otro para que este lo cause. Si bien la sanción para la mujer que aborte se encuentra en el Artículo 88 del Código Penal, también se citan los artículos 85, 86 y 87 para reflejar que el problema de la introducción del término "mujer" en los tipos penales estudiados se presenta tanto en el artículo 88 como en los artículos 85, 86 y 87.

En los artículos 85, 86, 87 y 88 del Código Penal, podemos observar que los mismos se encuentran dirigidos a quienes causaren un aborto, pudiendo este ser un profesional de la salud, o no, e incluso la misma mujer encinta. Los elementos determinantes del tipo que nos interesan son "...la mujer que causare su propio aborto o consintiere en que otro se lo causare ", "...con el consentimiento de la mujer”, “...sin el consentimiento de la mujer", $y$ "...seguidos de la muerte de la mujer". Se pone énfasis en esas formulaciones lingüísticas de la norma porque, valga la redundancia, son elementos determinantes del tipo, y esto quiere decir, que el aborto será punible en todos los casos de los artículos 85, 86, 87 y 88 cuando el aborto sea realizado sobre el cuerpo de una mujer, obviando que hoy en día no solo las mujeres pueden encontrarse encinta. 


\section{D.2.4. La Ley de Identidad de Género}

La ley de Identidad de Género en su artículo $1^{\circ}$ consagra el derecho a la identidad de género de la persona humana, al reconocimiento de su identidad de género, al libre desarrollo de su persona conforme a su identidad de género, y a ser tratada de acuerdo con su identidad de género y en particular a ser identificada de ese modo en los instrumentos que acreditan su identidad respecto de el/los nombres de pila, imagen y sexo con los que allí es registrada.

En su artículo $2^{\circ}$ se definen los alcances de lo que significa "identidad de género", que es entendida por esta ley como la vivencia interna e individual del género tal como cada persona la siente, la cual puede corresponder o no con el sexo asignado al momento del nacimiento, incluyendo la vivencia personal del cuerpo (el subrayado y las negritas me pertenecen).

Ahora bien, vamos a detenernos en esa definición de género como punto central de nuestro análisis de esta ley para establecer las reflexiones que podemos derivar de ella:

1) Una persona a quien se la designó mujer al momento de su nacimiento puede experimentar la vivencia interna e individual del género como la siente, y esta persona puede identificarse como hombre.

2) En base a la reflexión $n^{\circ} 1$ podemos entender al género como una construcción social y una vivencia interna e individual.

3) En línea con la reflexión $n^{\circ} 2$, podemos agregar que, el género es una construcción social pero que la vivencia interna e individual de una persona que se le asignó el género femenino al nacer, pero que se autopercibe como un hombre, no necesariamente quiere decir que esta no ejerza la vivencia personal de su cuerpo respecto de lo sexual y reproductivo como lo haría una mujer heterosexual, ni que resigne su función reproductiva de gestar por el mero hecho de autopercibirse como hombre.

4) Por todo lo anterior, y sin más preámbulo, es dable afirmar que hoy en día es posible, que un hombre trans -de 
género masculino, hablando en términos de género como la construcción social que es- pueda ser perfectamente capaz de gestar vida en su vientre.

5) Por consiguiente, si un hombre trans es capaz de gestar vida en su vientre, este también es potencialmente capaz para causarse un aborto, o consentir que le practiquen un aborto.

El articulado presente en la ley de género prosigue estableciendo la forma de ejercer este derecho y los requisitos para la rectificación del sexo, cambio de nombre, etc.

A su vez, se destaca en su Art. $4^{\circ}$ la innecesaridad de intervención quirúrgica genital, ni la acreditación de terapias hormonales u otro tratamiento, lo que reafirma la posibilidad de ejercer el cambio de sexo sin resignar las facultades reproductivas propias del sexo de nacimiento. La ley continúa expresando que, una vez cumplidos todos los requisitos establecidos en la misma, y con el cumplimiento del trámite del artículo $6^{\circ}$, el ejercicio del derecho surtirá los efectos contenidos en el artículo $7^{\circ}$ de la misma normativa.

El artículo $7^{\mathrm{a}}$ dispone que los efectos de la rectificación del sexo y el/los nombre/s de pila, realizados en virtud de la mencionada ley, serán oponibles a terceros desde el momento de su inscripción en el/los registros. Asimismo dispone que esta rectificación registral no alterará la titularidad de los derechos y obligaciones jurídicas que pudieran corresponder a la persona con anterioridad a la inscripción del cambio registral ni las provenientes de las relaciones propias del derecho de familia en todos sus órdenes y grados, las que se mantendrán inmodificables, de lo cual podemos inferir que, aún quienes ejerzan la rectificación de género, no solo podrán ejercer la paternidad/ maternidad como lo deseen si no que tampoco podrá alterarse la titularidad de los derechos y obligaciones jurídicas correspondientes a la persona que fueran anteriores al ejercicio de ese derecho -y este artículo es el que deja zanjado cualquier cuestionamiento respecto de la Ley de Identidad de Género como mecanismo de evasión de obligaciones legales-. 
Se introduce en el artículo 12 de la misma el derecho al trato digno; el trato digno se entiende como el respeto a la identidad de género adoptada.

Finalmente, para culminar, la Ley de Identidad de Género, en su artículo $13^{\circ}$ designa la obligatoriedad de su aplicación. Por lo que toda norma, reglamentación o procedimiento deberá respetar el derecho humano a la identidad de género de las personas. Ninguna norma, reglamentación o procedimiento podrá limitar, restringir, excluir o suprimir el ejercicio del derecho a la identidad de género de las personas, debiendo interpretarse y aplicarse las normas siempre a favor del acceso al mismo.

\section{E. Interpretación del artículo 88 del Código Penal Argentino a la luz de lo dispuesto por la Ley 26.743 de Identidad de Género}

\section{II.E.1. Un ejemplo de caso concreto}

En este apartado del presente trabajo, pasaremos a simular un caso concreto: en el caso propuesto una persona a quien se la designó como mujer al momento de su nacimiento, decide ejercer el derecho de rectificar su identidad de género, en función de que se autopercibe como hombre. Sin embargo, esta persona que ahora es un hombre, conforme las pautas fijadas por la Ley de Identidad de Género, ejerce su sexualidad de manera que se relaciona sexualmente con otros hombres y como resultado de esas vinculaciones, se embaraza. Más tarde decide interrumpir voluntariamente ese embarazo.

¿Cómo aplicaríamos la normativa penal que penaliza el aborto en este caso concreto? ¿A qué reflexiones podríamos arribar a partir del presente análisis?

De conformidad con las ideas de Zaffaroni tratadas en el inicio de esta monografía, el tipo penal es uno de los elementos del delito. Representa la base fáctica en torno a cuál gira la antijuricidad, la culpabilidad y la punibilidad; por lo que, si nuestra conducta a analizar no encaja en el tipo penal, la misma no es 
considerada típica, y como resultado no es posible aplicar la sanción prevista en ese tipo. La tipicidad es la correspondencia entre el hecho ocurrido en la realidad y el descrito en el tipo.

A su vez, la norma contiene elementos conceptuales del tipo, de carácter objetivo (descripción de hechos, cosas, personas, relaciones, sustentados en una naturaleza material objetiva, cuyo examen requiere una actividad mental sensorial cognoscitivo) y de carácter subjetivos (elementos psíquicos o internos del autor, que darán indicios o anticipos de antijuricidad, por ejemplo: situaciones anímicas como la emoción violenta). Existen otras clasificaciones de elementos del tipo penal que no son relevantes para la cuestión a tratar por lo que se las dejará de lado.

El problema que se nos presenta entre los artículos 85, 86, 87 y 88 del Código Penal y la Ley de Identidad de Género, se da en cómo la segunda afecta a los primeros respecto del tipo penal y sus elementos objetivos.

El elemento objetivo dado en los artículos 85, 86, 87 y 88 del Código Penal es "mujer"; para que la conducta descripta sea pasible de sanción, es estrictamente necesario que el elemento objetivo "mujer" se presente en el caso concreto en conjunto con la conducta penada del aborto.

Dado que, si en el caso concreto, un hombre trans, que es capaz de gestar vida en su vientre, decide interrumpir voluntariamente ese embarazo, y este caso fuera denunciado ante un juez, podrían darse dos escenarios:

1) El primero de los escenarios, sería el ejercicio del juez que aplicara los artículo 85, 86, 87 y 88 al caso a resolver, ignorando que el mencionado artículo no es pasible de ser aplicado porque no se cumple con los elementos del tipo, porque la Ley de Identidad de Género nos da una pauta clara de cómo debemos interpretar si una persona es una mujer o no lo es, y si esta pauta no se respeta, se estaría violando la aplicación de la Ley de Identidad de Género y todo lo dispuesto en ella -analizado ut-supra-, sin contar con que el juez estaría obviando 
categóricamente la prohibición de analogía in malam partem, principio implícito en materia de derecho penal.

2) El segundo de los escenarios sería el ejercicio del juez en el cual este reconoce la imposibilidad manifiesta de aplicar los artículos 85, 86, 87 y 88 para darle solución al hecho controvertido, porque el juzgamiento ajustado a derecho del caso que respete todas las garantías constitucionales de legalidad y del debido proceso, son a las claras incompatibles con la aplicación de los artículos 85 y consiguientes a este supuesto donde el aborto no fue realizado por una mujer, ni con el consentimiento de una mujer, ni sin el consentimiento de una mujer, por no ser una mujer la persona gestante que decidiera interrumpir ese embarazo.

En términos de legalidad, el segundo escenario parecería el más probable y el más ajustado a derecho. Sin embargo, esta potencial solución al caso también presenta un problema; dejar de lado la aplicación de los artículos 85, 86, 87 y 88 del Código Penal en este caso concreto, resultaría lesivo del principio de igualdad ante la ley en otros casos donde la persona que abortara fuera una mujer, haciendo una distinción solamente basada en el género, y en materia jurisprudencial se abriría una puerta difícil de cerrar; se estaría dejando la operatividad de la norma a la suerte de un criterio discriminatorio por el cual, las mujeres serían penadas por abortar, y los hombres serían absueltos aunque hubieran realizado la misma conducta.

\section{E.2. Frustración de la finalidad buscada por el legislador al penalizar el aborto}

La finalidad de la penalización del aborto es básicamente, "evitar" la práctica de abortos, a través de una teoría de prevención general negativa que lo que sostiene es que la pena funciona apuntando a la generalidad de los individuos de una sociedad buscando que la coerción o amenaza de sanción conlleve el cumplimiento de tales normas.

Pero lo cierto es que no solo la amenaza de una pena no logra evitar la práctica de la interrupción voluntaria de embarazos, si 
no que la prescripción normativa ni siquiera logra abarcar la universalidad de casos en los cuales podríamos identificar la conducta que se intenta evitar, todo esto como resultado de la inobservancia legislativa de la pertenencia del Código Penal a un sistema jurídico donde también existen normas que condicionan su aplicabilidad, sin mencionar que también existen principios que funcionan como criterios de aplicabilidad-como el principio de legalidad- que tornan incoherente al sistema jurídico y resulta en la inaplicabilidad de los artículos 85, 86, 87 y 88 del Código Penal.

\section{II.D. Relaciones entre normas y entre normas y principios desde el punto de vista de los sistemas normativos}

Según Alchourrón, habiéndose caracterizado el sistema de derecho como un sistema normativo cuya base está formada por enunciados de derecho válidos, que los juristas reformulen la base del sistema sustituyendo unos enunciados por otros, no afecta el contenido normativo y, por ende, la identidad del sistema, siempre que las consecuencias normativas sean las mismas. ${ }^{16}$

Esta circunstancia no se observa en el caso analizado, ya que sin quererlo con la promulgación de la ley de identidad de género, y todo lo que ella conlleva para la significación del género, tanto como esto afecta a los términos "hombre" y "mujer" y las prácticas biológicas intrínsecas de cada uno, se ignora que en los hechos se crea una categoría nueva de persona que no es mujer, que puede gestar, y que por lo tanto puede interrumpir esa gestación de manera voluntaria, y que la misma quedaría fuera de las consecuencias penales establecidas para esa conducta.

Al introducirse de esa manera el componente objetivo mujer, la figura del juzgador que tendrá a su cargo condenar o

\footnotetext{
16 Alchourrón \& Bulygin, Introducción a la metodología de las ciencias jurídicas y sociales, p.79.
} 
absolver al imputado de abortar cobra mayor relevancia, y este debe adaptarse al sistema jurídico, a sus normas y principios.

En este caso estaríamos ante un conflicto entre normas y principios. Luis Prieto Sanchís en su análisis de la obra de Ronald Dworkin, sostuvo:

“... pretende mostrarnos una realidad jurídica mucho más rica y compleja, impregnada de elementos morales y compuesta no solo por "normas" específicas, sino también por "principios" que, si bien no pueden identificarse mediante la regla de reconocimiento $u$ otro procedimiento análogo, deben ser y de becho son ponderados por el juez a la hora de decidir un determinado conflicto o supuesto de hecho, en particular cuando se trata de un "caso difícil" para el que no se encuentra respuesta satisfactoria en el derecho explícito. Este sería el caso en el que el juez debe ponderar la circunstancia de cada imputado (...) cuando se da un conflicto entre dos normas, una de ellas no puede ser válida, mientras que en los principios es necesario ponderar en cada caso el "peso" o importancia, de modo que su postergación ante un principio diferente no implica pérdida de vigor. Lo que supone, por tanto, que las normas constituyen tipos (estándares) fuertes, en el sentido de que ofrecen una razón suficiente para decidir el supuesto controvertido; los principios, en cambio, se presentan como modelos débiles, razones necesarias para decidir, pero que han de combinarse con otros elementos o criterios." ${ }^{17}$

Esos "otros elementos o criterios" serán las circunstancias particulares del caso que serán evaluadas el juzgador.

El juez que se encuentre frente al caso de un hombre trans que se ha practicado un aborto, deberá fallar por la absolución del imputado dado que este es inocente de cometer un aborto a la luz de lo dispuesto por los arts. 85, 86, 87 y 88 si tenemos en cuenta que el sujeto acusado no es una mujer. En sí mismo parece un caso sencillo de resolver si se emplean

17 Prieto Sanchís, "Teoría del Derecho y Filosofía Política en Ronald Dworkin", pp. 356 y s.s. 
adecuadamente las garantías y los principios penales propios del debido proceso. La dificultad surgiría al momento de juzgar con el mismo articulado a la mujer que se practique un aborto. El juez en ese caso -como en todo el resto de los conflictos judiciales- deberá contrastar las normas penales con principios, y teniendo en cuenta que los hombres trans serían inimputables del delito de abortar, resultarían explícitamente incoherentes las normas del Código Penal que sancionaran a la mujer por abortar frente al Principio de Igualdad ante la Ley consagrado en el artículo. 16 de la Constitución Nacional.

Según Dworkin, principios y reglas tienen ambas estructuras, y funciones diferentes, ya que se pueden sintetizar en 1) distintas maneras de regular las conductas; 2) distintas maneras de determinar su pertenencia a un ordenamiento jurídico.

Las reglas se aplican a las conductas "a todo o nada"; y los principios en cambio, dependen de la ponderación de los distintos principios en juego, de las consecuencias de la decisión y de un conjunto de circunstancias particulares que no se presentan ni se discuten cuando se juzga la aplicabilidad de una regla.

En nuestro caso de análisis las normas que se aplican "a todo o nada" son los artículos 85, 86, 87 y 88 del Código Penal, y con "a todo o nada" nos referimos a que el caso debe presentar todos los elementos del tipo para aplicar esas normas, y uno de los elementos necesarios es que el sujeto de la conducta sea una mujer, caso contrario, si el sujeto que aborta no es una mujer, la norma no será aplicable y por lo tanto el caso deberá ser desestimado.

Dentro del género de los principios Dworkin distingue entre directrices -los estándares que proponen un objetivo a ser alcanzado, una mejora en algún rasgo- y los principios en sentido estricto -como estándares que deben observarse ya que constituyen exigencias de "justicia equidad, o alguna otra dimensión de la moralidad-". ${ }^{18}$

18 Dworkin, Barcelona, Los derechos en serio, p. 72. 
El principio de igualdad -incluso en cuestiones de génerono es solo una mera directriz, es un principio irrenunciable y un estándar que debe observarse en todo momento, ya que es la base de un debido proceso y del sistema de procesamiento de personas por cometer conductas típicas antijurídicas y culpables. De lo contrario, no habría criterio razonable para encarcelar y excarcelar personas, resultando en que el texto penal pasaría a ser inconstitucional y por lo tanto inútil a los fines de impartir justicia.

Nos refiere Alonso que Alexy, al respecto de conflictos entre reglas y principios, aporta otra óptica, ya que según la misma los conflictos entre reglas solo se solucionan introduciendo una cláusula de excepción que elimina el conflicto, o declarando inválida una de las reglas. ${ }^{19}$

El problema es que cuando dos principios colisionan, el conflicto no se soluciona anulando un principio o incluyendo una excepción, sino a través de una ley de colisión que funciona de manera que en ciertos casos un principio prevalece sobre el otro, aplicando los mismos como mandatos de optimización, en la medida de que los hechos jurídicos y el universo de casos fácticos lo requieran. Un ejemplo sería la colisión entre el principio de Igualdad ante la ley, y el principio del Respeto a la Vida Humana, dado por la aplicación que debe hacerse de los artículos 85, 86, 87 y 88 del Código penal en acusadas de abortar que son mujeres y la no aplicación de estos en acusados de abortar por no ser mujeres -no solo internamente, sino que también avalados por la ley-.

Introduciendo su óptica propia, Hart establece que los principios son más generales que las reglas debido a que un número determinado de reglas puede ser mostrado como un ejemplo de un principio; y que los principios hacen referencia a objetivos, metas, valores, propósitos, facultades o ideales que se presentan como algo deseable de conservar o de incluir,

19 Alonso, Interpretación de las normas y derecho penal", p. 168. 
otorgando una explicación y una racionalidad subyacente de las reglas, y también contribuyendo a su justificación. ${ }^{20}$

Según el criterio de Hart, el principio es una generalidad, y aunque varias reglas puedan demostrar el cumplimiento de un principio, no siempre es así porque como se expuso al principio de este trabajo, las normas no aplican siempre a la totalidad de los casos. Si los principios se presentan como estándares de algo que se desea conservar e incluir, no se puede pensar en hacer excepciones cuando de aplicar una norma se trata dejando de lado un principio, menos aun cuando del Principio de Igualdad se trata, ya que el Principio de Igualdad es el principio que protege a los sujetos de derecho de condenas arbitrarias por excelencia, cuando, en definitiva, el derecho -sin sujetos- no es más que un conjunto de formulaciones normativas dotadas de significado.

\section{Conclusión}

En el caso de la penalización del aborto, se observa claramente como la imposibilidad fáctica de que el creador de normas contemple la totalidad de los casos que podrían requerir de la aplicación de esas normas, colisiona con los principios que el sistema normativo toma como metanormas; todo ello con la mera introducción de leyes que en principio parecería tener nula relación con la conducta prohibida.

La aplicación de los artículos 85, 86, 87 y 88 del Código Penal, son susceptibles de cometer graves violaciones al principio de igualdad ante la ley, que se encuentra consagrada en el artículo 16 de la Constitución Nacional. Si una mujer aborta, y es penada por ello, mientras al mismo tiempo, un hombre trans que aborta, no es penado, se estaría dejando de lado el principio de igualdad únicamente por una diferenciación de género.

Entonces, la valoración o "ponderación" que hará el juzgador del caso, resulta determinante para que una persona quede

20 Ibídem, p. 171. 
con un estatus o categoría jurídica distinta del resto de los ciudadanos que realizan la misma conducta.

En una valoración más personal y alejada de las temáticas tratadas en el presente trabajo, creo que este problema jurídico se encuentra dado por una innegable falta de instrucción respecto de políticas y perspectivas de género, que dan lugar a que se perpetúen legislaciones lesivas de derechos humanos; machistas, porque en los casos propuestos a lo largo de este trabajo podemos observar que hay conductas delictivas que pueden ser cometidas tanto por hombres como por mujeres. Sin embargo, estas conductas solo son penadas cuando son cometidas por mujeres, dado que siempre se limitó a la mujer a su función reproductiva. Incluso hoy en día se mantiene la idea de que las mujeres somos "incubadoras de la vida humana" y al ser esa nuestra "función intrínseca" se nos debe castigar por decidir no cumplir con ella.

Asimismo, la transfobia instalada en varios sectores de la sociedad niega que hay personas que no se auto perciben de acuerdo con el sexo que le fue asignado al momento de su nacimiento, y a raíz de esa negación tampoco de observa que hoy un hombre puede portar la capacidad biológica de gestar vida en su vientre, y como consecuente, también es sujeto pasible de abortar.

Más allá de que cada ciudadano puede tener una postura tomada respecto de un tema y eso es perfectamente válido -y en función de ello quién evalúe mi trabajo puede estar de acuerdo, o no, con mis consideraciones personales-, estimo que es innegable el hecho de que las leyes, están hechas para ser cumplidas, con arreglo a la debida coherencia que deben presentar esas leyes conviviendo en un mismo sistema.

Es por todo ello que, aunque podamos estar de acuerdo, o no, con la legislación existente respecto del aborto, o del trato igualitario hacia las personas que se perciben de un género distinto al asignado en su nacimiento, no podemos ignorar que aún se siguen incumpliendo las leyes que los amparan como 
sujetos de derecho que son, y como titulares de un derecho humano que aún es puesto en duda por una gran parte de la población.

Todos somos sujetos de derecho, y todos somos en mayor o menor medida titulares de derechos humanos. Reconocer la titularidad de nuestros propios derechos humanos, pero negar la existencia de aquellos con los cuales no estamos de acuerdo, es una práctica peligrosa, porque en definitiva ¿Quién está facultado para decirle al otro, que sus los derechos humanos que detenta son menos válidos que los que detentamos nosotros mismos?

En cuanto a las cuestiones jurídicas, concluyo que ante el presente conflicto normativo se presentan dos posibles soluciones:

1) Derogar la normativa de los arts. 85, 86, 87 y 88 del Código Penal, por resultar desactualizada, transfóbica, lesiva de los derechos fundamentales de igualdad ante la ley y los derechos humanos relativos a la sexualidad y la identidad de género.

2) Actualizar el texto de la normativa de los artículos 85, 86, 87 y 88 del Código Penal con miras a incluir a todos los individuos que puedan ser potenciales gestantes, como mujeres, hombres y personas no binarias -aún más, implementar el uso del lenguaje inclusivo para evitar nuevamente una falta grave de inclusión de todos los seres gestantes, y no vulnerándose así el principio de igualdad-.

Como último comentario, dejo planteada la necesidad de comenzar a implementar el lenguaje inclusivo no solo como medio lingüístico cotidiano y para respetar los deseos y concepciones de todas las personas, también como lenguaje científico pretendiendo zanjar estas cuestiones de discriminación y exclusión de antemano. 


\section{Bibliografía}

AlchourRón \& Bulygin (1987). Introducción a la metodología de las ciencias jurídicas y sociales, Astrea, Buenos Aires.

Alchourrón, Bulygin (1991). Análisis lógico y Derecho, Madrid.

Alonso (2006). Interpretación de las normas y derecho penal, Edit. Del Puerto, Buenos Aires.

CSJN (1991) "Comunidad Homosexual Argentina c. Resolución Inspección General de Justicia".

CSJN (2006) "Asociación Lucha por la Identidad Travesti - Transexual c/ Inspección General de Justicia".

Dworkin (1984). Los derechos en serio, Ariel, Barcelona, Traducción de Marta Guastavino.

Kelsen (1987). Teoría pura del derecho, Editorial Eudeba, Buenos Aires, Argentina.

Prieto Sanchís (1985). "Teoría del Derecho y Filosofía Política en Ronald Dworkin", en Revista Española de Derecho Constitucional, Año 5. Núm. 14, pp. 356 y s.s.

RoDRíguez (2017). "Lagunas axiológicas y relevancia normativa", en DOXA, Cuadernos de Filosofía del Derecho, 40, Buenos Aires.

Zaffaroni, Alagia, Slokar (2005). Derecho Penal Parte General, Segunda edición, Sociedad Anónima Editora, Comercial, Industrial y Financiera, Buenos Aires. 